\title{
Stereo- and Oligo-controlled Synthesis of Oligo[p-phenylene-(E)-vinylene]-p-benzoic Acid Derivatives: Basic Building Blocks for Oligo[p-phenylene-(E)-vinylene]s
}

\author{
Tze-Lock Chan, Hak-Fun Chow,* Sun Fong, Man-kit Leung*, $\dagger$ and Jingren Tu \\ Department of Chemistry, The Chinese University of Hong Kong, Shatin, NT, Hong Kong
}

Oligo[p-phenylene-(E)-vinylene]benzoic acids of up to four aromatic units are synthesized in complete oligo- and excellent $(E)$-stereo-control via an iterative modified Ramberg-Bäcklund reaction; these extended $\pi$-systems can be used to construct oligo [ $p$-phenylene $(E)$-vinylene]s in good yields.

The search for novel electrically conducting materials is of fundamental and practical interest to the electronic industry. ${ }^{1}$ The past decade has witnessed a rapid development in synthetic methodologies for organic polymers with conjugated polyaromatic or polyene chains for evaluaton as electrical conductors and non-linear optical materials. ${ }^{2}$ One particular class of conjugated polymer is poly(phenylene-vinylene) (PPV) which is based on the stilbenoid structure. ${ }^{3}$ However, the high polydispersity and low solubility of PPVs in organic solvents, along with the occurrance of geometrical isomerism, have hampered detailed studies of their physical properties and limited their applications. As a result, geometricallydefined oligomeric model systems of PPV that possess sufficient solubility in organic solvents have been synthesized ${ }^{4}$ and submitted for tests of their electrochemical properties. ${ }^{1 c}$

There are only a limited number of synthetic routes to oligo(phenylenevinylene)s (OPVs). ${ }^{3}$ In this communication we report a new synthetic approach which allows the iterative assemblage of OPVs in complete oligo- and excellent $(E)$ stereo-control. The basic building blocks for the synthesis of OPVs are the lower oligo[p-phenylene- $(E)$-vinylene $]$ - $p$-benzoic acid derivatives 1 and 2 . These carboxylic acid derivatives can be synthesized in good yields and high $(E)$-stereoselectivities (Scheme 1) using a modified Ramberg-Bäcklund procedure. ${ }^{5}$ Starting from methyl 4-bromomethylbenzoate 3 , the corresponding methyl xanthate $4 \ddagger$ could be obtained in quantitative yield. ${ }^{6}$ Treatment of 4 with sodium methoxide in methanol led to the thiol 5 , which was coupled in situ to 3,5-di-tert-butylbenzyl bromide to give the thioether $\mathbf{6 a} \neq$ in $70 \%$ overall yield. The thioether $6 \mathbf{a}$ was then oxidized with oxone $^{7}$ in refluxing methanol to yield the sulfone $7 \mathbf{a}+$ as a crystalline solid in $81 \%$ yield. The sulfone methyl ester 7a was then subjected to a modified Ramberg-Bäcklund procedure employing alumina-supported potassium hydroxide-dibromodifluoromethane-tert-butyl alcohol ${ }^{5}$ at $5-10{ }^{\circ} \mathrm{C}$, in the course of which hydrolysis of the ester linkage occurred to afford the stilbene carboxylic acid 1a $\ddagger$ in $80 \%$ yield. The presence of only an $(E)$-carbon-carbon double bond $(J=16.4 \mathrm{~Hz})$ was revealed in the ${ }^{1} \mathrm{H}$ NMR spectrum of this acid and the signals for the three aromatic protons of the 3,5-di-tert-butylphenyl ring coincided as a sharp singlet $(\delta 7.40)$. A small amount $(<2 \%)$ of the corresponding methyl ester 2 a could also be detected, indicating that the hydrolysis was just short of completion under the reaction conditions. The mixture of carboxylic acid 1a and methyl ester $2 \mathbf{a}$ was then converted to the corresponding benzyl chloride $\mathbf{8 a}+$ in $81 \%$ yield via a reduction (lithium aluminum hydride)-chlorination (thionyl chloride) sequence. The chloride $8 \mathbf{a}$ served as the starting material for the next higher homologue of $1 a$ and the first iterative reaction cycle was completed.

The next iterative cycle began with the coupling of 8a with 4 to give the thioether $\mathbf{6 b} \ddagger$ in $81 \%$ yield. The sulfone $7 \mathbf{b}, \ddagger$ synthesized from the thioether $6 \mathbf{b}$ in $90 \%$ yield, was subjected to the one-flask Ramberg-Bäcklund procedure ${ }^{5}$ to give a $2: 3$ mixture of the (styryl)stilbene carboxylic acid $\mathbf{1 b} \ddagger$ and the corresponding methyl ester $2 \mathbf{b} \ddagger$ in $90 \%$ total yield. The $(E)$-configurations of both double bonds in either the acid $\mathbf{1 b}$ $(J=16.2$ and $15.7 \mathrm{~Hz})$ or the methyl ester $\mathbf{2 b}(J=16.3$ and $16.0 \mathrm{~Hz}$ ) were confirmed by ${ }^{1} \mathrm{H}$ NMR and again no $(Z)$-isomer could be detected. The presence of an extra styryl substituent probably increases the hydrophobicity of the sulfone $\mathbf{7 b}$ and hence retards the rate of heterogeneous ester hydrolysis and a mixture of acid and ester was formed. Reduction of this mixture with lithium aluminum hydride followed by chlorination of the resulting alcohol gave the homologous benzyl chloride $8 \mathrm{~b} \neq$ in $58 \%$ overall yield.

Repeating the same iterative synthetic sequence, the chloride $8 \mathbf{b}$ was converted to the sulfone $7 \mathrm{c} \neq$ via the thioether $\mathbf{6 c} \dagger$ in overall $45 \%$ yield. Application of the RambergBäcklund reaction methodology on the sulfone $7 \mathrm{c}$ gave a $10: 1$. mixture of the methyl ester $2 \mathbf{c} \ddagger$ and the carboxylic acid $\mathbf{1 c}$. In compound $2 c$, while the merged ${ }^{1} \mathrm{H}$ NMR signals (s, $\delta 7.14$ ) for the central double bond precluded stereochemical assignment, nevertheless the $(E)$-configurations of the newly formed and the terminal double bonds were ascertained by the two large coupling constants $(J=16.4$ and $14.3 \mathrm{~Hz})$ in the ${ }^{1} \mathrm{H}$

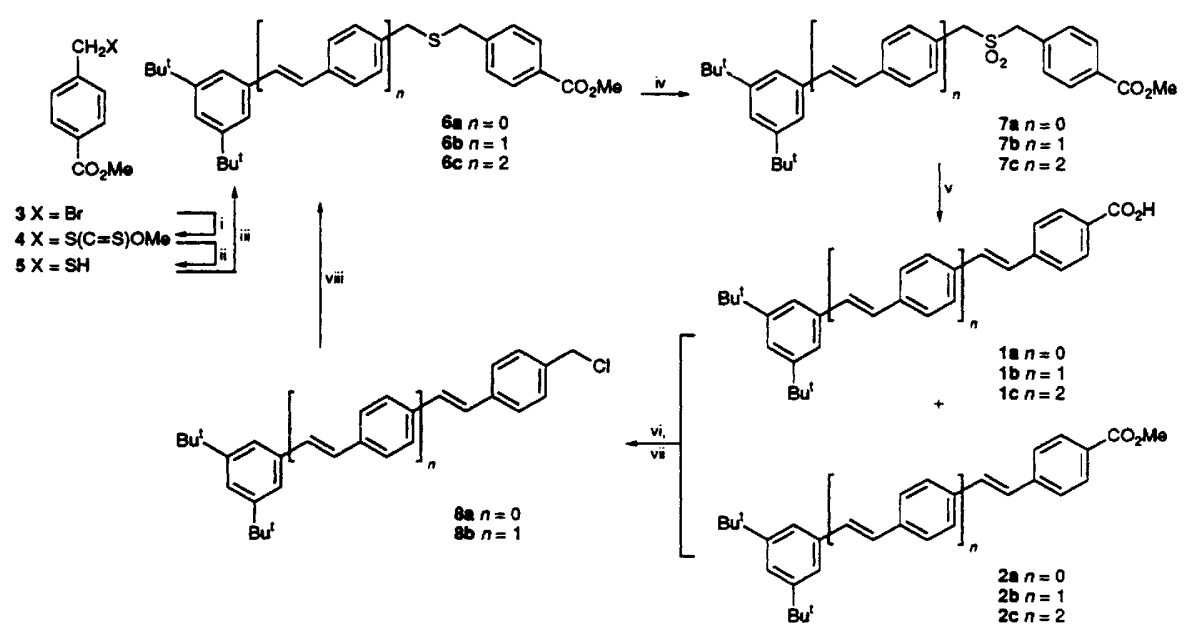

Scheme 1 Reagents: i, $\mathrm{CS}_{2}, \mathrm{KOH}, \mathrm{MeOH}, \mathrm{THF}$;i, NaOMe, MeOH; iii, NaOMe, 3,5-di-tert-butylbenzyl bromide, MeOH; iv, oxone, MeOH; v, $\mathrm{KOH}-\mathrm{Al}_{2} \mathrm{O}_{3}, \mathrm{CBr}_{2} \mathrm{~F}_{2}, \mathrm{Bu}^{\mathrm{t} O H}$; vi, $\mathrm{LiAlH} 4$, THF; vii, $\mathrm{SOCl}_{2}, \mathrm{CCl}_{4}$; viii, $4, \mathrm{NaOMe}, \mathrm{MeOH}$ 


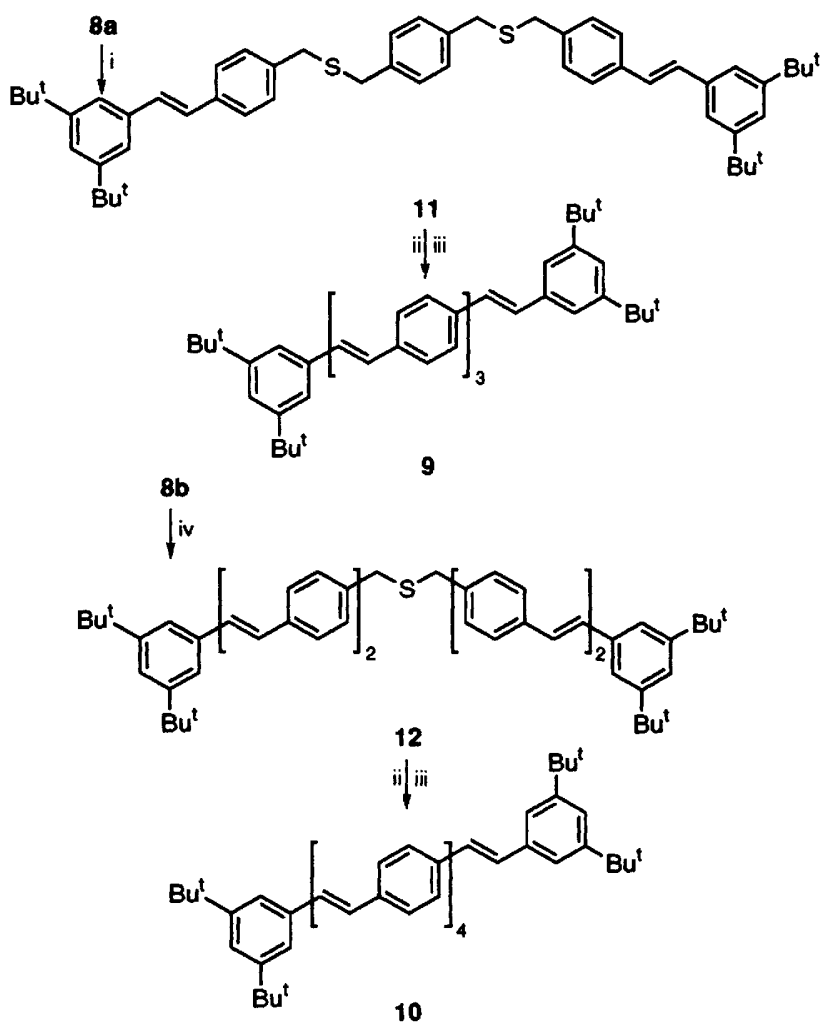

Scheme 2 Reagents: i, 1,4-bis(mercaptomethyl)benzene, $\mathrm{KOH}$, EtOH, $\mathrm{CH}_{2} \mathrm{Cl}_{2}$; ii, oxone, $\mathrm{MeOH}$; iii, $\mathrm{KOH}-\mathrm{Al}_{2} \mathrm{O}_{3}, \mathrm{CBr}_{2} \mathrm{~F}_{2}, \mathrm{Bu}^{\mathrm{t} O H}$; iv, $\mathrm{Na}_{2} \mathrm{~S}, \mathrm{CH}_{2} \mathrm{Cl}_{2}, \mathrm{EtOH}$

NMR spectrum. Since no other olefinic protons could be detected, we concluded an all $(E)$-stereochemistry for the trienic ester $2 \mathbf{c}$.

To demonstrate that these carboxylic acid derivatives such as $\mathbf{1}$ or $\mathbf{2}$ are useful building blocks for the synthesis of OPVs, the conjugated pentamer 9 and hexamer 10 were prepared (Scheme 2). The pentamer 9 was assembled by a $[2+2+1]$ coupling method. Thus, 2 equivalents of the benzyl chloride $8 \mathbf{a}$ were coupled to 1 equivalent of the linker 1,4-bis(mercaptomethyl)benzene to give the bis-sulfide 11 in $87 \%$ yield. Oxidation of the bis-sulfide 11 with oxone followed by the Ramberg-Bäcklund reaction gave the pentamer $9 \ddagger^{4 a}$ in $81 \%$ overall yield. The hexamer 10 , on the other hand, was constructed using a $[3+3]$ coupling protocol. The benzyl chloride 8b was self-coupled with sodium sulfide to give the symmetrical thioether $12, \ddagger$ which was converted to the conjugated hexamer $10 \$^{4 a}$ via the corresponding sulfone, employing the Ramberg-Bäcklund conditions in $70 \%$ overall yield. For the pentamer 9 , the ${ }^{1} \mathrm{H}$ NMR of the newly formed olefinic protons appeared coincidentally as a singlet $(\delta 7.13)$; while for the hexamer 10, the olefinic protons of the newly formed central double bond are chemically equivalent. As a result, the $(E)$-stereochemical configurations of these newly formed double bonds are difficult to confirm. Nonetheless, both the pentamer 9 and hexamer 10 were isolated as a single compound from the reaction mixture. Since no $(Z)$-stilbenes have ever been isolated from the modified Ramberg-Bäcklund reactions of primary dibenzylic sulfones, 5 we believe that all the double bonds in compounds 9 and $\mathbf{1 0}$ exist solely in $(E)$-configurations.

In conclusion, we have demonstrated that our modified Ramberg-Bäcklund reaction conditons can be used to synthesize oligo $[p$-phenylene- $(E)$-vinylene]benzoic acid derivatives and oligo[p-phenylene- $(E)$-vinylene]s in good yields and in excellent $(E)$-stereoselectivities. No $(Z)-(E)$ isomerisation is necessary as compared to the Wittig olefination employed by Müllen. ${ }^{4} a$ By choosing the appropriate benzyl chloride 8 , OPVs of different chain lengths can be synthesized. This method therefore offers a high degree of flexibility and versatility. These oligo[phenylene- $(E)$-vinylene]benzoic acid derivatives can also be linked to a polymeric backbone to generate polymers which may have interesting optical, photochemical and photophysical properties. ${ }^{8}$

We thank the Research Grants Council, Hong Kong for an Earmarked Grant (CUHK90/93E).

Received, 16th May 1994; Com. 4/02877E

\section{Footnotes}

$\dagger$ Present address: Department of Chemistry, National Taiwan University, Taipei, Taiwan, Republic of China.

$\ddagger$ All new compounds were characterized on the basis of their ${ }^{1} \mathrm{H}$ and ${ }^{13} \mathrm{C}$ NMR spectra, mass spectral data and elemental analyses, for which satisfactory results were obtained. Physical and selected spectral data for: $1 \mathrm{a}: \mathrm{mp} 230-232{ }^{\circ} \mathrm{C} ; \delta_{\mathrm{H}}\left(\mathrm{CDCl}_{3}, 250 \mathrm{MHz}\right) 1.37(18$ $\left.\mathrm{H}, \mathrm{s}, 2 \mathrm{Bu}^{\mathrm{t}}\right), 7.13(1 \mathrm{H}, \mathrm{d}, J 16.4, \mathrm{CH}=\mathrm{C}), 7.30(1 \mathrm{H}, \mathrm{d}, J 16.4, \mathrm{C}=\mathrm{CH})$, $7.40(3 \mathrm{H}, \mathrm{s}, \mathrm{ArH}), 7.62(2 \mathrm{H}, \mathrm{d}, J 8.4, \mathrm{ArH})$ and $8.11(2 \mathrm{H}, \mathrm{d}, J 8.4$, $\mathrm{ArH}) ; \delta_{\mathrm{C}}\left(\mathrm{CDCl}_{3}, 62.5 \mathrm{MHz}\right) 31.5,34.9,121.2,122.9,126.3,126.9$, $127.8,130.7,133.1,136.1,143.2,151.3$ and 171.0 .1 b: $\mathrm{mp} 290-292^{\circ} \mathrm{C}$. 2b: $m p$ 189-190 ${ }^{\circ} \mathrm{C}$. 2 c: $m p ~ 266-267^{\circ} \mathrm{C}$. 4: $\mathrm{mp} 32-34^{\circ} \mathrm{C}$. 6a: $\mathrm{mp} 44-46$ ${ }^{\circ} \mathrm{C}$. 6b: mp 52-54 ${ }^{\circ} \mathrm{C}$. 6c: $\mathrm{mp} 144-147^{\circ} \mathrm{C}$. 7a: $\mathrm{mp}$ 203-204 ${ }^{\circ} \mathrm{C}$. $7 \mathrm{~b}: \mathrm{mp}$ 183-185 ${ }^{\circ} \mathrm{C}$. 7c: $\operatorname{mp~} 253-255^{\circ} \mathrm{C}$. 8a: $\mathrm{mp} 110-111{ }^{\circ} \mathrm{C}$. 8b: mp 163164 ${ }^{\circ} \mathrm{C}$. 9: $\mathrm{mp} 281-285^{\circ} \mathrm{C}$ (lit. ${ }^{4 a} \mathrm{mp} 294^{\circ} \mathrm{C}$ ); $\delta_{\mathrm{H}}\left(\mathrm{CDCl}_{3}, 270 \mathrm{MHz}\right.$ ) $1.37\left(36 \mathrm{H}, \mathrm{s}, 4 \mathrm{Bu}^{\mathrm{t}}\right), 7.09(2 \mathrm{H}, \mathrm{d}, J 16.2,2 \mathrm{C}=\mathrm{CH}), 7.13(4 \mathrm{H}, \mathrm{s}, 2$ $\mathrm{CH}=\mathrm{CH}), 7.19(2 \mathrm{H}, \mathrm{d}, J 16.5,2 \mathrm{HC}=\mathrm{C}), 7.35-7.38(6 \mathrm{H}, \mathrm{m}$, terminal $\mathrm{ArH})$ and $7.53(12 \mathrm{H}, \mathrm{s}$, internal $\mathrm{ArH}) .10: \mathrm{mp}>290^{\circ} \mathrm{C}$ (lit. ${ }^{4 a} \mathrm{mp} 307$ $\left.{ }^{\circ} \mathrm{C}\right) ; \delta_{\mathrm{H}}\left({ }^{2}[\mathrm{H}]_{8} \mathrm{THF}, 250 \mathrm{MHz}\right) 1.36\left(36 \mathrm{H}, \mathrm{s}, 4 \mathrm{Bu}^{\mathrm{t}}\right), 7.15(2 \mathrm{H}, \mathrm{d}, J$ $16.5,2 \mathrm{C}=\mathrm{CH}), 7.22(6 \mathrm{H}, \mathrm{s}, 3 \mathrm{CH}=\mathrm{CH}), 7.26(2 \mathrm{H}, \mathrm{d}, J 16.5,2 \mathrm{HC}=\mathrm{C})$, $7.36(2 \mathrm{H}, \mathrm{d}, J 2$, terminal ArH $), 7.42(4 \mathrm{H}, \mathrm{d}, J 2$, terminal ArH $)$ and $7.56\left(16 \mathrm{H}, \mathrm{s}\right.$, internal ArH). 12: $\mathrm{mp} 191-194{ }^{\circ} \mathrm{C}$.

\section{References}

1 For general references see: (a) Conjugated Polymers. The Novel Science and Technology of Highly Conducting and Nonlinear Optically Active Materials, ed. J. L. Brédas and R. Silbey, Kluwer Academic Publishers, Dordrecht, 1991; (b) P. Bäuerle, Adv. Mater., 1993, 5, 879; (c) Conjugated Polymers and Related Materials, The Interconnection of Chemical and Electronic Structure, ed. W. R. Salaneck, I. Lundström and B. Rånby, Oxford University Press, Oxford, 1993.

2 For examples see: (a) A. Kiehl, A. Eberhardt, M. Adam, V. Enkelmann and K. Müllen, Angew. Chem., Int. Ed. Engl., 1992, 31, 1588; (b) L. Duhamel, P. Duhamel, G. Plé and Y. Ramondenc, Tetrahedron Lett., 1993, 34, 7399.

3 H. Meier, Angew. Chem., Int. Ed. Engl., 1992, 31, 1339; R. A. Wessling, J. Polym Sci., Polym. Symp. 1985, 72, 55; P. M. Lahti, D. A. Mordarelli, F. R. Deuton, III, R. W. Lenz and F. E. Karasz, J. Am. Chem. Soc., 1988, 110, 7259; P. L. Burn, D. D. C. Bradley, R. H. Friend, D. A. Halliday, A. B. Holmes, R. W. Jackson and A. Kraft, J. Chem. Soc., Perkin Trans 1, 1992, 3225; J. H. Burroughes, D. D. C. Bradley, A. R. Brown, R. N. Marks, K. MacKay, R. H. Friend, P. L. Burn and A. B. Holmes, Nature, 1990, 347, 539.

4 (a) R. Schenk, H. Gregorius, K. Meerholz, J. Heinze and K. Müllen, J. Am. Chem. Soc., 1991, 113, 2634; (b) U. Scherf and K. Müllen, Synthesis, 1992, 23; (c) H. Gregorius, M. Baumgarten, R. Reuter, N. Tyutyulkov and K. Müllen, Angew, Chem., Int. Ed. Engl., 1992, 31, 1653.

5 T. L. Chan, S. Fong, Y. Li, T.-O. Man and C.-D. Poon, J. Chem. Soc., Chem. Commun., in the press.

6 A. I. Vogel, A Textbook of Practical Organic Chemistry, 4th edn., The English Language Book Society and Longman, London, 1978, p. 588 .

7 B. M. Trost and D. P. Curran, Tetrahedron Lett., 1981, 22, 1287.

8 For examples, see W. M. Gibbons, R. P. Grasso, M. K. O'Brien, P. J. Shannon and S. T. Sun, Macromolecules, 1994, 27, 771; K. J. Dorst, V. P. Rao and A. K.-Y. Jen, J. Chem. Soc., Chem. Commun., 1994, 369. 